\title{
Critical Success Factors in Enterprise Wide Information Management Systems Projects
}

\author{
Mary Sumner \\ Southern Illinois University Edwardsville \\ Campus Box 1106 \\ Edwardsville, IL 62026 \\ 618-650-2093 \\ Msumner@siue.edu
}

\begin{abstract}
In the past several years many organizations have initiated enterprise-wide information management systems projects, using such packages as SAP, Peoplesott, and Oracle. These projects often represent the single largest investment in an information systems project in the history of these companies, and in many cases the largest single investment in any corporate-wide project.
\end{abstract}

These enterprise-wide information management systems projects bring about a host of new questions. Some of these questions and issues are:

- How are these projects justified?

- Do firms need to change their fundamental business processes, organizational structures, and business strategies to fit the package?

- What are the technical challenges associated with implementing a large-scale package such as SAP?

- What is the best way to implement a large-scale package: To work through the organization unit-byunit? Or to use a cross-functional approach?

- What are the critical success factors in the implementation of a large-scale package?

- What are the implications of these projects for the skill and knowledge requirements of the IT workforce?

This paper will provide case studies of seven organizations implementing enterprise-wide information management systems projects and will provide insight into each of these questions based upon their experiences.

\section{BACKGROUND:}

Some of the "success factors" associated with large-scale client-server implementation projects include securing the support of top management (Beath, 1991), improving or "re-

Permission to make digital or hard copies of all or part of this work for personal or classroom use is granted without fee provided that copies are not made or distributed for protit or commercial advantage and that copies bear this notice and the full citation on the first page. To copy otherwise, to republish, to post on servers or to redistribute to lists. requires prior specific permission and/or a fee.

SIGCPR '99 New Orleans LA USA

Copyright ACM 1999 1-58113-063-5/99/04 ..\$5.00 engineering" business processes before implementing IT solutions (Hammer and Champy, 1993), and assuring close involvement between users and the IT organization (Mumford, 1981).

With new technology, it is often critical to acquire external expertise, including vendor support, to facilitate successful implementation. Also, the costs of training and support are often under-estimated, and these costs may be many times greater than originally anticipated. Client-server implementations often bring "surprises" with respect to cost, because of the costs of decentralized servers, systems integration software, technical support, and software updates and version control (Caldwell, 1996).

The lessons learned from systems development projects can also pose some challenges for large-scale integrated projects. Some of the "best practices" in project management include effective external integration strategies, such as creation of a user steering committee, user participation on the project team, and user responsibility for education and installation (Cash, McFarlan, 1992). In addition, successful projects require the use of effective internal integration strategies, such as use of outside technical expertise, selection of an experienced project manager, and selection of team members with significant previous work relationships.

Other systems development practices which contribute to project success are effective project planning, effective change control, business justification, compatibility of skills with the skill set needed for project requirements, and leadership by a "champion" who markets the project internally (Beath, 1991).

\section{CAUSES OF PROJECT FAILURES:}

Much has been written about the causes of information systems project failures. Poor technical methods is only one of the causes, and this cause is relatively minor in comparison to larger issues, such as failures in communications and ineffective leadership.

In Robert Block's analysis, there are twelve categories which classify most system failures. These are summarized in the following table: 


\begin{tabular}{|c|c|c|}
\hline Failure & Cause & Result \\
\hline 1. Resource failures & $\begin{array}{l}\text { Conflicts of people, time and project } \\
\text { scope due to insufficient personnel. }\end{array}$ & $\begin{array}{l}\text { Incorrect systems with poor } \\
\text { reliability, difficulty with } \\
\text { maintenance, and dissatisfied users. }\end{array}$ \\
\hline 2. Requirement failures & Poor specification of requirements. & $\begin{array}{l}\text { Leads to developing the wrong } \\
\text { system with many changes in } \\
\text { requirements downstream. }\end{array}$ \\
\hline 3. Goal failures & $\begin{array}{l}\text { Inadequate statement of system goals } \\
\text { by management. }\end{array}$ & $\begin{array}{l}\text { Leads to developing the wrong } \\
\text { system by leading to requirement } \\
\text { failures. }\end{array}$ \\
\hline 4. Technique failures & $\begin{array}{l}\text { Failure to use effective software } \\
\text { development approaches, such as } \\
\text { structured analysis/design. }\end{array}$ & $\begin{array}{l}\text { Causes inadequate requirements } \\
\text { specification, poor reliability, high } \\
\text { maintenance costs, scheduling and } \\
\text { budget problems. }\end{array}$ \\
\hline 5. User contact failures & $\begin{array}{l}\text { Inability to communicate with the } \\
\text { system user. }\end{array}$ & $\begin{array}{l}\text { Causes inadequate requirements } \\
\text { specification, and poor preparation } \\
\text { for accepting and using the } \\
\text { information systcm. }\end{array}$ \\
\hline 6. Organizational failures & $\begin{array}{l}\text { Poor organizational structure, lack of } \\
\text { leadership, or excessive span of } \\
\text { control. }\end{array}$ & $\begin{array}{l}\text { Leads to poor coordination of tasks, } \\
\text { schedule delays, and inconsistent } \\
\text { quality. }\end{array}$ \\
\hline 7. Technology failures & $\begin{array}{l}\text { Failure of hardware/software to meet } \\
\text { specifications; failure of the vendor } \\
\text { to deliver on time, or unreliable } \\
\text { products. }\end{array}$ & $\begin{array}{l}\text { Cause schedule delays, poor } \\
\text { reliability, maintenance problems, } \\
\text { and dissatisfied system users. }\end{array}$ \\
\hline 8. Size failures & $\begin{array}{l}\text { When projects are too large, their } \\
\text { complexity pushes the organization's } \\
\text { systems development capabilities } \\
\text { beyond reasonable limits. }\end{array}$ & $\begin{array}{l}\text { Caused by insufficient resources, } \\
\text { inadequate requirements } \\
\text { specifications, simplistic project } \\
\text { control, poor use of methodology, } \\
\text { and poor organizational structure. }\end{array}$ \\
\hline 9. People management failures & $\begin{array}{l}\text { Lack of effort, stifled creativity, and } \\
\text { antagonistic attitudes cause failures. }\end{array}$ & $\begin{array}{l}\text { Time delays and budget overruns } \\
\text { occur, project specifications are poor, } \\
\text { and the system is difficult to } \\
\text { maintain. }\end{array}$ \\
\hline 10. Methodology failures & $\begin{array}{l}\text { Failure to perform the activities } \\
\text { needed, while unnecessary activities } \\
\text { are performed. }\end{array}$ & $\begin{array}{l}\text { This type of failure can lead to any of } \\
\text { the consequences of system failure. }\end{array}$ \\
\hline 11. Planning and control failures & $\begin{array}{l}\text { Caused by vague assignments, } \\
\text { inadequate project management and } \\
\text { tracking tools. }\end{array}$ & $\begin{array}{l}\text { Work assignments may overlap, } \\
\text { deliverables may be poorly defined, } \\
\text { and poor communication may result. }\end{array}$ \\
\hline 12. Personality failures & These are caused by people clashes. & $\begin{array}{l}\text { Passive cooperation and covert } \\
\text { resistance, with possible acts of } \\
\text { vengeance. }\end{array}$ \\
\hline
\end{tabular}

In summary, Block points out that successful projects are ontime and within budget, reliable, maintainable, and meet the goals and requirements of users. Block points out that managers who succeed do an initial evaluation of a project. They evaluate the rules, the players, the goals, the constraints, and the project manager's responsibility and authority, and well as the feasibility of success (Block, 1983). Managers should recognize and implement strategies to minimize the risk of failure, as outlined in the above table.

\section{RESEARCH QUESTIONS:}

- What is the purpose and scope of the enterprise-wide information management systems project?

- What are the project objectives and outcomes to date?
- How was the investment in the integrated system justified? What were the tangible and intangible business benefits that were considered?

- What was the role and importance of top management support?

- How were business processes affected by the software?

- What investments in training, support, and maintenance were needed to assure project success?

- Was external vendor expertise used to accomplish certain aspects of the project?

- What was the role of end-users in project management and systems development? 


\section{FINDINGS:}

The findings describe seven casc studies which have been accomplished as a "pilot" study for this research. These case studies will highlight the issues of project justification, benefits, critical success factors, and factors associated with project "failure." They deal with three SAP Projects, two Peoplcsoft Projects, and two Oracle Projects.

\section{ENTERPRISE-WIDE PROJECTS USING SAP: Monsanto:}

Monsanto is one of the world's largest chemical and life sciences companies. Since becoming chairman and chief executive in 1995, Robert Shapiro has intensified the transformation of Monsanto from a pioneering chemical company to a cutting-edge bioengineering company with a concentration on food and nutrition. The focus of Monsanto's business is a $\$ 2$ billion drug division, a $\$ 1.2$ billion food ingredients division, and a $\$ 3$ billion maker of agricultural products. This $\$ 6$ billion group of companies is positioned to lead the biotech revolution of the future.

\section{Project Justification:}

Beginning in 1996, Monsanto started a corporate-wide SAP project. The business justification for the project was operational excellence, e.g. cutting the costs of core transactions-processing systems, such as order processing and inventory management. In addition, an integrated package could support worldwide business operations and replace division-level systems. Before SAP, Monsanto had four purchasing packages-one for each business unit. SAP provided economies of scale in development, maintenance and operations. Its overall costs were divided by a much larger number of users. For example, buying a $\$ 100,000$ package to support 5000 users is less expensive than buying a $\$ 25,000$ package to support 100 users. In addition, the SAP project enabled Monsanto to reduce its information systems development staff from 500 to 50 people.

Some of the "business drivers" for the SAP implementation at Monsanto included: data integration, standardization, access to timely and complete information, leverage gained in purchasing, and globalization. SAP cut the costs of operational systems, improved the reliability of customer service, and assured timely delivery and follow-up.

\section{Critical Success Factors:}

Some of the "critical success factors" in the Monsanto project dealt with the management structure, the re-design of business processes, investments in re-skilling and professional development, and acquisition of external expertise.

- Management structure: Monsanto put someone "in charge" and centralized the management structure of the project in order to avoid duplication of effort.
- Re-design of business processes. Rather than attempting to modify the software, Monsanto reengineered their business processes to be consistent with the software. This has proved to be critical to the project's success. Many companies "go to war" with the package and try to make it meet their process requirements, only to lead the way to huge cost overruns and project failure in some cases.

- Training and re-skilling. Monsanto invested heavily in training and re-skilling their developers in SAP software design and methodology.

- External consultants. When they didn't have needed expertise internally, Monsanto brought in the consultants they needed.

- Management support. Without question, top management support is critical to the success of a project, and the SAP project had approval by top management.

- Role of the champion. The project leader for the SAP project was clearly a "champion" for the project, and that role was critical to marketing the project throughout the organization.

- Discipline and standardization. Another "success factor" which is closely associated with the software itself is the need to adhere with the standardized specifications that the software supports.

- Effective communications. Another important CSF is to tell everyone in advance what is happening, including the scope, objectives, and activities of the project. Admit that there will be change.

- Obtain "business" analysts. One of the critical workforce requirements for the project was the ability to obtain analysts with both "business" and technology knowledge. Instead of 200 "programmers" with average skills, the SAP project demanded and could be accomplished with 20 of the "best and brightest" analysts. However, retaining these professionals was a significant problem because of their market value.

In terms of factors conducive to project failure, one of the main factors associated with failure is lack of integration. The project needs to be based on an enterprise-wide design. You can't start with "pieces," and then try to integrate the software component's later on. Other problems are caused by "going to war" with the package, and trying to modify the code to conform with existing business processes. As mentioned earlier, this is a sure formula for potentially huge cost overruns and possible project failure.

In terms of "lessons learned," Monsanto's experience demonstrated the importance of using SAP's built-in "best practices," its systems development methodology, and a combination of systems analysts with both "business" sense and knowledge of information technology. Other "lessons" are: start with small, empowered teams; standardize data early on; eliminate complexity; and avoid compromising the system and its specifications. Standardization is key to success, and can create greater flexibility and changeability down the line.

Monsanto considered their project a success because of a centralized management structure, adherence to design 
specifications, and investments in training and support required to overcome technical and procedural challenges in design and implementation.

\section{Anheuser Busch Companies:}

Anheuser Busch Companies initiated a corporate-wide SAP project in 1996. The project is perhaps the largest IT project ever undertaken by the company. Anheuser Busch is a worldwide manufacturer of beer and related food products, headquartered in St. Louis, Missouri.

\section{Project Justification:}

The original project justification was similar to the one at Monsanto. There were extensive economies of scale associated with consolidating four MIS projects into one, and SAP offered an integrated, corporate-wide solution. The business justification entailed major cost savings from reducing the costs of operational level information systems. SAP provided hard-dollar savings, based upon integration of data and processes, a common database, and increased leverage in purchasing and buying.

\section{Critical Success Factors:}

The critical success factors mentioned by Anheuser Busch's senior project manager for the SAP project included:

- Maintain excellent staffing, both by developing internal personnel and by using external consultants.

- Place a "business" leader in charge, so that project leadership comes from the business perspective.

- Avoid trying to modify the software; instead, re-design or re-engineer existing business processes to "fit" what the software will support.

- Obtain and maintain top management support for the project.

- Obtain and retain team members with knowledge of the business processes, as well as an understanding of the technical aspects.

- Understand the role of the "champion" in marketing the project's success throughout the organization.

Three of the "lessons learned" in the Anheuser Busch case were to obtain the "right" people for the project, empower the team, and take the training seriously. Recruiting and retaining qualifed SAP systems developers was a critical issue, as was the cost and availability of training.

\section{Sigma Chemical:}

\section{Project Justification:}

The major sources of justification for the SAP project at Sigma Chemical were the need to integrate a number of different order processing systems, the need to improve and integrate financial systems, and the ability to reduce the workforce through systems integration. The major motivation behind the project was to gain a "competitive advantage" by providing "seamless" order processing to customers in a global marketplace. This meant that any customer in the world could place orders using one integrated order processing system, as opposed to using many different systems for different product lines.

\section{Project Management:}

The project team at Sigma consisted of 30 individuals, with 10 consultants and 20 internal people. Consultants were rotated in and out of the project, with some being "weeded out." The project team consisted of both "business" and "system" types.

\section{Technical Issues:}

One of the major technical issues faced at Sigma was the capacity of servers on a client-server network. Because of capacity issues, SAP requires "maintrame-like" operating system performance in a PC-network operating system environment.

\section{Critical Success Factors:}

Some of the major "critical success factors" for the SAP Project included:

- Achieve the support of senior management for accomplishing project goals and objectives and aligning these with strategic business goals.

- Re-design business processes to be consistent with system specifications.

- Invest in training, re-skilling, and professional development of the IT workforce.

- Use a mix of consultants and internal staff to work on the project team, so that internal staff members can "grow" the necessary technical skills for SAP design and implementation.

- Make a major commitment to training end-users in system uses.

\section{ENTERPRISE-WIDE PROJECTS USING PEOPLESOFT:}

\section{Boeing Company:}

\section{Project Justification:}

The Peoplesoft Project at Boeing was justified in terms of better information, cost-reduction, and data integration. Between 70 and 80 systems were replaced by a single, integrated system. While the original intent was to implement an integrated human resources/payroll system using Peoplesoft, the first phase of the project involved completing the human resources (HR) component and creating an interface to the existing McDonnell Douglas Corporation (MDC) payroll system. After the completion of the MDC-Boeing merger, the plan was to integrate both HR and payroll, using the Peoplesoft software. As you will learn later, this "phased-in" approach created significant problems in system implementation. 


\section{Project Management:}

Originally, the Boeing Peoplesoft team consisted of 80 to 100 members which migrated to the project from legacy systems development units within the divisions. Each project component utilized Peoplesoft consultants and consultants from contractors.

\section{Critical Success Factors:}

The CSF's in Boeing's Peoplesoft project were similar to those already mentioned for the various SAP projects. First and foremost was the importance of using a "vanilla" implementation, e.g. "not changing the original software." In the Boeing case, a number of pieces of the Peoplesoft software were customized. In its implementation, for example, the HR piece was $70 \%$ vanilla, $30 \%$ custom. The payroll piece was $60 \%$ vanilla, and $40 \%$ custom; and the benefits piece was $50 \%$ vanilla, $50 \%$ custom. One of the most difficult and time-consuming aspects of the project was the creation of a "bridge" between the HR and legacy payroll application, and this resulted in extensive time and cost delays.

To summarize some of these Critical Success Factors:

- Use a "federal" approach; define what is needed at the entreprise-level, and then apply it to the business unit level.

- Obtain strong top management sponsorship.

- Use a common data model and common data definitions to drive common business processes.

- Obtain a full-time commitment of "customers" to project management and project activities.

- Use a "vanilla" approach; avoid customization.

- If modifications are necessary, establish an up-front agreement between IT and user managers with respect to what is to be modified.

- Avoid technological bottlenecks (e.g. Boeing did not have a client workstation configuration ready).

- Re-skill the end-users in new technologies and applications.

- Supplement "generalized" user training with training in the use of specific application modules.

- Make a commitment to training and re-skilling technical professionals.

- Train, train, train.

- Be sensitive to user resistance.

- Establish disciplined, flexible program management.

Boeing's project encountered a number of difficulties and challenges which were not within the project's control. These included organizational re-structuring, user resistance to change, and management structure. To briefly summarize the impact and implications of each of these issues:

- Organizational re-structuring: The Boeing/McDonnell Douglas merger complicated the project and necessitated the creation of a "bridge" between the Peoplesoft HR software and the MDC legacy system, resulting in extensive time and cost delays. In addition, different "technology" environments at Boeing and
MDC have created delays in establishing consistency and coordination in platforms, database management systems, and operating system environments for the Peoplesoft application. For example, the choice of whether to implement Peoplesoft using Unix/Oracle as an operating system/database environment or MVS/DB2 is still pending. While Unix/Oracle is the "standard" environment at MDC, MVS/DB2 is the system standard at Boeing.

- User resistance to change: Once data input was decentralized to the shop floor at McDonnell Douglas as part of the Peoplesoft HR system implementation, there was major resistance by end-users. This reinforces the critical importance of training.

- Management structure: Another, more complex issue is related to the problem of having too many "chief s." At $M D C$, three different vice-presidents (including the HR head, the IT head, and the Finance VP) all had the same authority and conflicts arose in establishing common requirements. In implementing a "centralized" system, centralized authority must "call the shots."

Finally, in terms of the "lessons learned" from the Boeing project, there were recurring themes: standardization, reskilling, addressing client-server technological implementation issues up front, and effective team management. Some of these lessons include:

- Attempts at customization will bring about unnecessary time and cost delays and should be avoided.

- Training costs may be higher than expected.

- It may be difficult to get managers to commit to project management roles, because they may be uncertain about what responsibilitics will still be open to them once they are transferred back to their functional areas.

- It is difficult to recruit and retain good technical people because market rates for these people are much higher.

- It is important to prepare for client-server implementation well in advance.

- It is important to implement a total integrated package at one time, rather than in pieces. The building of a bridge between a Peoplesoft module and a legacy application was problematic and proved this point.

- Manage team expectations effectively.

- Mandate change; there will be change.

\section{Edward Jones Company:}

\section{Project Justification:}

The major justification for the Peoplesoft Project at Edward Jones was data integration, a common systems approach, and hard dollar savings through integration.

\section{Critical Success Factors:}

The critical success factors for this project, as with many of the others, were:

- Obtaining top management sponsorship;

- Putting a steering committee in charge; 
- Recruiting and retaining "key” Peoplesoft people.

\section{Lessons Learned:}

The "lessons learned" included other strategies common to many of the other projects, including: avoiding customization and getting the "business" areas to dedicate people to the management of the project.

\section{ENTERPRISE-WIDE PROJECTS USING ORACLE:}

\section{Ralston PurinaCompany:}

\section{Project Characteristics:}

The Oracle Financials Project at Ralston Purina supported a modular approach, with the implementation of "add-on" modules in manufacturing. Since Ralston is a divisionalized company, the Oracle projects were accomplished on a division-by-division basis.

\section{Project Justification:}

The Oracle project was justified in terms of data integration and cost-reduction through the re-engineering of business processes.

\section{Project Management:}

The project included over 100 people on teams with 8 to 9 team members and 2-3 external consultants composing each team. The consultant/internal staff mix facilitated crosstraining and the ability to "grow" internal staff members with the needed technical skills. It was absolutely critical to obtain consultants with technical expertise in the implementation of specific modules, such as $A / R$ and $G / L$. Understanding how to use consultants as "subject-area" specialists is critical to project success.

\section{Critical Success Factors:}

Some of the CSF's for the Oracle project at Ralston included similar "messages," such as the need for strong management sponsorship, experienced technical consultants, and experienced project managers. Some new strategies included:

- Address "scope expansion" requests with information on the time, cost, and business impacts of these changes;

- Address "tough" issues squarely. Surprises hurt trust.

- Bring all "related" projects together and manage them.

- Avoid customization (e.g. don't touch the software, don't touch the Oracle tables, don't touch the Oracle interfaces).

- Don't add people to a project, if it is already behind schedule.
- Obtain consultants who are specialists in specific application modules.

- Understand and appreciate the criticality of high-tech worker turnover, recruitment, and retention issues.

- Emphasize reporting, including custom report development, the use of report generators, and user training in reporting applications.

- Emphasize effective user training.

\section{Emerson Electric Company:}

\section{Project Characteristics and Justification:}

The major purpose of the project was to implement Oracle financial, distribution, and manufacturing systems. The business justification included: inventory reduction, headcount savings, and reduced lead times through on-time delivery.

\section{Project Management:}

Each Oracle project was accomplished with an internal team of 25 , augmented by 50 to 60 external consultants and an additional 50 users. The extensive use of consultants was necessary because of project completion dates, which dictated bringing in high-demand skills, rather than developing these skills in-house. This meant considerably higher costs than the costs that would have been incurred through the re-skilling of internal IT professionals.

\section{Technical issues:}

The major technical issues dealt with migrating toward a server-based architecture. Avoiding client workstation implementations helped to facilitate completion of technical activities.

\section{Critical Success Factors:}

Some of the CSF's in the project re-iterated strategies expressed in the interviews with many of the other companies, and included;

- Obtain top management support for the project.

- Obtain IT top management support for the project.

- Re-design business processes to support the software.

- When software does not meet requirements, use bolton's, or add-on packages which are offered by Oracle or third-party vendors.

- In some cases, when software does not meet user requirements, create manual workarounds, including such things as the use of bar-coding.

- Make a commitment to user training.

- Maximize use of consultants.

\section{Lessons Learned:}

- Break the project into smaller phases if possible. A phased-in approach is superior to the "big-bang," all-atonce approach. 
- Limit the number of "bolt-on's," or "add-on's," to those which are absolutely critical to accomplishing project activities.

\section{SUMMARY AND CONCLUSIONS:}

These large integrated information systems projects pose new opportunities and significant challenges. Based upon these preliminary case studies, it seems that the risk of project failure is being contained primarily through a number of strategies.

- Justify the enterprise-wide projects based upon costjustification and economies of scale.

- Re-engineer business processes to "fit" the package, rather than trying to modify the software to "fit" the organization's current business processes.

- Identify and implement strategies to re-skill the existing IT workforce and acquire external expertise through vendors and consultants when needed.

- Utilize "business analysts," with both business knowledge and technology knowledge.

- Obtain top management support for the project and a commitment to establishing and supporting project leadership.

- Make a commitment to training ene-users in custom report development.

Without question, the effective management of these huge projects is a new and unique challenge which requires the use of project management and control methods that have not been used extensively in the past. The sheer size of these projects requires centralized control, strict discipline, and extensive monitoring of project outcomes. Compared with traditional MIS projects, less emphasis is placed upon defining user requirements and organizing system processes to support these needs. The risk is that using a large-scale package such as SAP to support the business creates a more centrally controlled, consistent organizational structure and moves away from supporting unique business requirements at the business unit level.

\section{REFERENCES:}

Beath, C. "Supporting the information technology champion," MIS Quarterly, V. 15, No. 3, 1991, pp. 355-373.

Block, Robert. The Politics of Projects, Yourdon Press, Prentice-Hall, 1983.

Caldwell, B. "Client-Server: can it be saved?" Information Week, V. 584, 1996, pp. 36-44.

Hammer, M. and Champy, J., Re-engineering the Corporation: A Manifesto for Business Revolution, Nicholas Brearley Publishing, London, 1993.

Cash, J, McFarlan, F.W., McKenney, J, and Applegate, L, "A Portfolio Approach to IT Development," Corporate Information Systems Management, Irwin Publishing, Third Edition, 1992.

Mumford, E., "Participative systems design: structure and method. Systems, Objectives, Solutions. V. 1, No. 1, 1981, pp. 5-19. 